Revista Española de Antropología Americana

ISSN: 0556-6533

https://doi.org/10.5209/REAA.63691

\title{
La guadúa que se corta: paisajes culturales y patrimonio construido en la costa ecuatoriana (Manabí, Ecuador) ${ }^{1}$
}

\author{
Manuel Castro Priego ${ }^{2}$, Manuel Alejandro Barcia Moreira ${ }^{3}$, \\ Marcos Octavio Labrada Ochoa ${ }^{4}$ y Edison Aroldo Chasing Guagua ${ }^{5}$
}

Recibido: 17 de mayo de 2017 / Aceptado: 24 de septiembre de 2018

Resumen. El bambú y la madera generaron una arquitectura nueva durante el primer periodo de expansión cacaotera (siglos XVIII-XIX) en Ecuador, marcada por influencias europeas. El estudio de las construcciones se ha realizado tradicionalmente en términos monumentalistas. Gran parte de ellas se encuentran en peligro de desaparición como resultado de las reducidas políticas locales de conservación, la escasez de normativas de protección, y una pérdida de las tradiciones en torno a la explotación del bambú. La investigación plantea un estudio multidisciplinar en el área sur de la provincia de Manabí, con un primer acercamiento etnográfico. Se analizan las posibilidades de desarrollo en torno a la protección del espacio urbano más emblemático de la arquitectura en guadúa, la ciudad de Jipijapa. Al mismo tiempo, se examina la construcción de nuevos paradigmas «culturales» en la región costera del Ecuador como resultado de la reformulación del Estado ecuatoriano. La nueva realidad surgida sitúa en un segundo plano los tradicionales «patrimonios culturales dominantes», siendo uno de los más representativos la arquitectura del periodo cacaotero.

Palabras clave: caña guadúa; arquitectura del cacao; paisajes culturales; Jipijapa; etnografía.

\section{[en] Bamboo that Is Cut: Cultural Landscapes and Built Heritage on the Ecuadorian Coast (Manabí, Ecuador)}

\begin{abstract}
During the first cocoa expansion period in Ecuador (18th and 19th centuries), bamboo and wood gave rise to a new style of architecture, marked by European influences. Study of these constructions has traditionally been done in monumentalist terms. A significant portion of these structures are in danger of collapse as a result of reduced local conservation policies, inadequate protection standards, and a decline in traditional methods of bamboo exploitation. The research proposes a multidisciplinary study in the southern area of the province of Manabí, with a first ethnographic approach. It analyses the possibilities of development around the protection of the most emblematic urban space of the architecture in guadua, the city of Jipijapa. At the same time, it examines the construction of new «cultural» paradigms in the coastal region of Ecuador as a result of the reformulation of the Ecuadorian State. The new reality situates in the background the traditional «dominant cultural patrimonies», one of the most representative is the architecture of the cocoa period.
\end{abstract}

Keywords: guadua cane; cocoa architecture; cultural landscapes; Jipijapa; etnography.

\footnotetext{
${ }^{1}$ La investigación se desarrolló durante una estancia dentro del Programa Prometeo de Manuel Castro Priego, promovida por la Secretaría de Educación Superior, Ciencia, Tecnología e Innovación (SENESCYT) de la República del Ecuador. También ha sido sufragada dentro del Programa de Investigación de la Universidad Estatal del Sur de Manabí (UNESUM) y el proyecto «Articulación de un modelo de protección del Patrimonio Cultural de Jipijapa», del que Manuel Castro fue Investigador Principal (IP).

2 Universidad de Alcalá, España. manuel.castro@uah.es

3 Instituto Nacional de Patrimonio Cultural, Ecuador. manuel.barcia@patrimoniocultural.gob.ec

4 Instituto Nacional de Patrimonio Cultural, Ecuador. marcos.labrada@patrimoniocultural.gob.ec

5 Universidad Estatal del Sur de Manabí, Ecuador. edison.chasing@unesum.edu.ec
} 
Sumario. 1. Introducción. 2. Materiales y métodos. 3. Resultados y discusión. 4. Conclusiones. 5. Referencias.

Cómo citar: Castro Priego, Manuel, Manuel Alejandro Barcia Moreira, Marcos Octavio Labrada Ochoa y Edison Aroldo Chasing Guagua. 2018. «La guadúa que se corta: paisajes culturales y patrimonio construido en la costa ecuatoriana (Manabí, Ecuador)». Revista Española de Antropología Americana 48: 79-103.

\section{Introducción}

La arquitectura tradicional en el área noroccidental de América del Sur (costa pacífica de Colombia, Ecuador y Norte de Perú) se ha caracterizado por el empleo intenso del bambú, especialmente de una de sus subespecies conocidas como caña guadúa o brava (Guadua Angustifolia Kunth). Su uso, que se origina con anterioridad al periodo colonial, continuó siendo dominante hasta la década de los 50 del pasado siglo. En la actualidad, sigue formando parte del conjunto de recursos de la arquitectura costeña, aunque lentamente es sustituida por nuevos materiales. Su utilización histórica, descrita desde el siglo XVI (Juan y Ulloa 1748; Benzoni 2000), originó unas técnicas de edificación específicas, no sólo por la tipología de las construcciones, sino por su identificación con un determinado modo de organización productiva y estructuración social.

Las ventajas bioclimáticas que ofrece la caña brava se ven contrarrestadas por la perdurabilidad del material, que no alcanza más allá de 120-130 años si no se actúa con programas de conservación y restauración ${ }^{6}$. Frente a la difusión de la arquitectura del sector serrano del Ecuador, con lugares tan emblemáticos como Quito o Cuenca, el patrimonio cultural edificado de la costa (Esmeraldas, Manabí, Guayas y Los Ríos) (Figura 1) resulta todavía un gran desconocido.

Gran parte de la arquitectura histórica que se conserva en el ámbito urbano en el suroeste de la República del Ecuador, fue construida en el periodo entre 1880 y 1940. Se trata en la mayor parte de los casos de edificios vinculados con el surgimiento de una burguesía, que apoyó su poder económico en la producción agrícola del cacao (Pineo 1994; Acosta 2006). A lo largo del siglo XX, y ante la generalización de la crisis cacaotera y el hundimiento de precios a partir de 1925, tendrán cada vez un mayor peso otros productos agrarios: el café, el banano y la continuidad de las exportaciones del sombrero de paja toquilla, que se venía produciendo desde el siglo XVIII (Chiriboga 2013: 383-393).

Junto a la globalización, existen otros elementos que están contribuyendo a la desaparición de la arquitectura en guadúa: normativas de protección insuficientes a nivel local, escasa concienciación social de su importancia, reducida gestión de sus posibilidades de desarrollo económico a través de su mantenimiento y sostenibilidad. Algunas de estas dificultades se observaron durante el terremoto de abril de 2016, que afectó con especial virulencia al sector costero ecuatoriano ${ }^{7}$. Esta inves-

\footnotetext{
6 No existen propuestas extensas de restauración de las construcciones en guadúa, en Ecuador. Se han planteado estudios evolutivos, de naturaleza formal, como por ejemplo los de M. A. Camino (Camino 2011). Hay, sin embargo, ejemplos en la región de análisis urbanísticos y arquitectónicos con materiales similares a los tratados en este trabajo, especialmente en Colombia (Niglio 2012).

7 El terremoto que afectó a Ecuador en el mes de abril de 2016, significó un daño notable en el patrimonio arqui-
} 


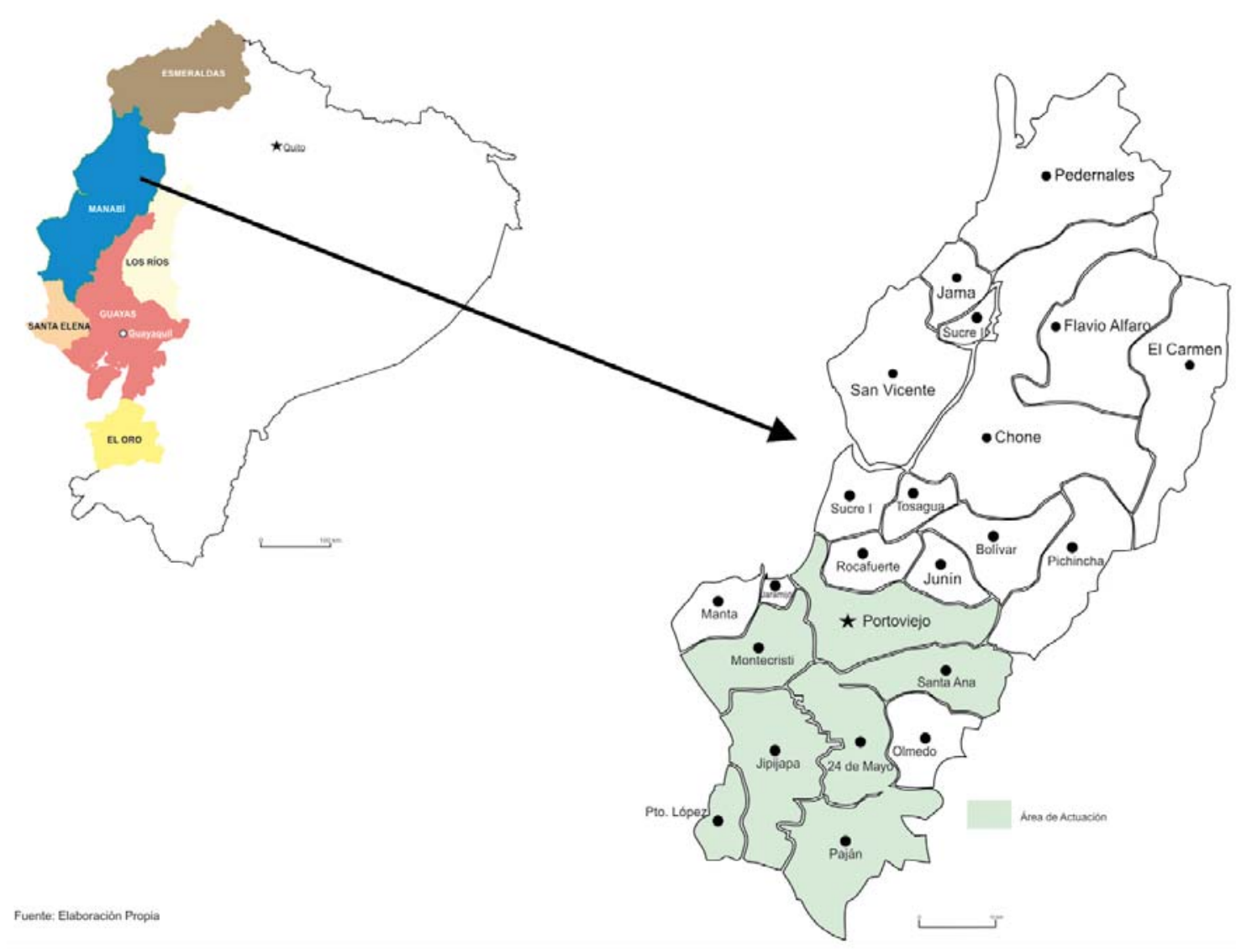

Figura 1. La región de la costa de Ecuador y los cantones de Manabí.

tigación analiza la construcción de modelos de difusión y revalorización del patrimonio cultural edificado en uno de los sectores centrales de la costa, la provincia de Manabí (Ecuador) (Figura 1), a partir de programas regionales y micro-espaciales.

El objetivo de la investigación es obtener un análisis crítico del proceso de construcción de modelos en torno a la protección y revalorización de un patrimonio cultural en peligro desde una perspectiva holística en un área geográfica concreta (el sur de Manabí, Ecuador). Hasta ahora, gran parte de los análisis en torno a la arquitectura en bambú han carecido de un análisis antropológico y se han centrado en exclusiva en criterios descriptivistas, que no han mostrado interés por la cadena operativa y la integración social en torno a la guadúa. Pero al mismo tiempo, se pretende identificar los límites de la difusión de la institucionalización del patrimonio cultural, en un área en la que se están conformando nuevas alternativas de desarrollo en torno a él, que coinciden con la reformulación del Estado ecuatoriano de principios del siglo XXI. Se produce así un proceso de revalorización de lo indígena o lo prehispánico, opuesto a lo colonial, como reflejo de una tensión social en torno a la desigualdad, que fluye dentro de pautas folkloristas y que establecerá distintas categorizaciones de patrimonio cultural de cara al futuro. 


\section{Materiales y métodos}

La investigación del presente estudio es de naturaleza cualitativa, basada en un análisis multidisciplinar que combina estudios sobre los procesos tradicionales de extracción, explotación y transformación de la caña guadúa, con una aproximación a las fuentes documentales del periodo republicano y colonial (siglo XVIII-XIX). Se procedió también a una identificación tipológica-evolutiva de las construcciones a lo largo del sector suroccidental de la provincia de Manabí (Ecuador). Por último, se realizó un acercamiento a la percepción ciudadana en torno al patrimonio construido y su conservación. Gran parte del estudio tiene como núcleo central la ciudad de Jipijapa (Manabí, Ecuador), que mantiene uno de los conjuntos arquitectónicos más importantes de la costa ecuatoriana, muy unido al crecimiento y expansión del cacao y el café ${ }^{8}$ como productos alimentarios «industriales», entre finales del siglo XIX e inicios del siglo XX. La investigación se desarrolló durante un año (2015-2016) y estuvo integrada por un equipo diverso, conformado por arquitectos, antropólogos, arqueólogos, juristas y especialistas en medioambiente de diversas nacionalidades.

\subsection{La caña guadúa: un material abundante y sostenible. Características etno- gráficas}

Uno de los elementos centrales del estudio fue la identificación de la actividad antrópica en torno a la producción de la guadúa. Las características de la caña le permiten ser una sustituta de la madera, no sólo por su nivel de resistencia, sino por la facilidad de crecimiento y reproducción. La guadúa pertenece a una subfamilia de los bambús (Figura 2a) que suele habitar en las inmediaciones de las quebradas y riberas de los ríos. Tradicionalmente, se ha interpretado como una especie muy vinculada a la actividad antrópica en el bosque tropical ${ }^{9}$. La especie presenta pequeñas diferencias, marcadas por su coloración (bicolor o negra). En el caso ecuatoriano predomina la tonalidad verde, con franjas blancas en los nudos. Es conocida como «brava», «mansa» o «guadúa», dependiendo del número de ramas con espinas que muestra la parte inferior de la planta (Banik 2015). Su geografía es amplia; aparece en áreas costeras, pero también en zonas por encima de $1.500 \mathrm{msnm}$. La planta puede alcanzar los 30 años de vida, aunque su madurez se sitúa entre los 4 y 7 años. La altura máxima puede llegar a $30 \mathrm{~m}$, con un grosor de hasta $20 \mathrm{~cm}$ de diámetro. $\mathrm{Su}$ protección y la medición de su densidad y superficie es uno de los aspectos centrales de los estudios ambientales que se están realizando en Colombia (Kleinn y Morales 2006), Ecuador o Brasil. La caña asegura la recuperación de suelos convertidos en pasto, tras un largo proceso de explotación agraria y ganadera (Rodríguez et al. 2009) y supone un importante reservorio de humedad.

\footnotetext{
8 Existen diversos estudios sobre el impacto del cultivo del café en las comunidades agrarias a lo largo de América Latina. Entre otros, para Costa Rica (Sick 1999) y El Salvador (Lauria 1999). Un estudio amplio sobre las consecuencias de la llegada de la globalización a través de la United Fruit Company al sur de Ecuador desde los años 30 del siglo XX, se encuentra en el trabajo de Striffler ( 2002).

9 La recuperación de macrofósiles en el suroeste de la Amazonía, con una datación entre 3,2 millones de años y 45.000 BP (Olivier et al. 2009: 4; McMichael 2014), resuelve la datación de su aparición en el continente. Su presencia es, por tanto, muy anterior a la aparición humana, que se está fechando en torno al 17.000 BP (Fiedel 2000).
} 

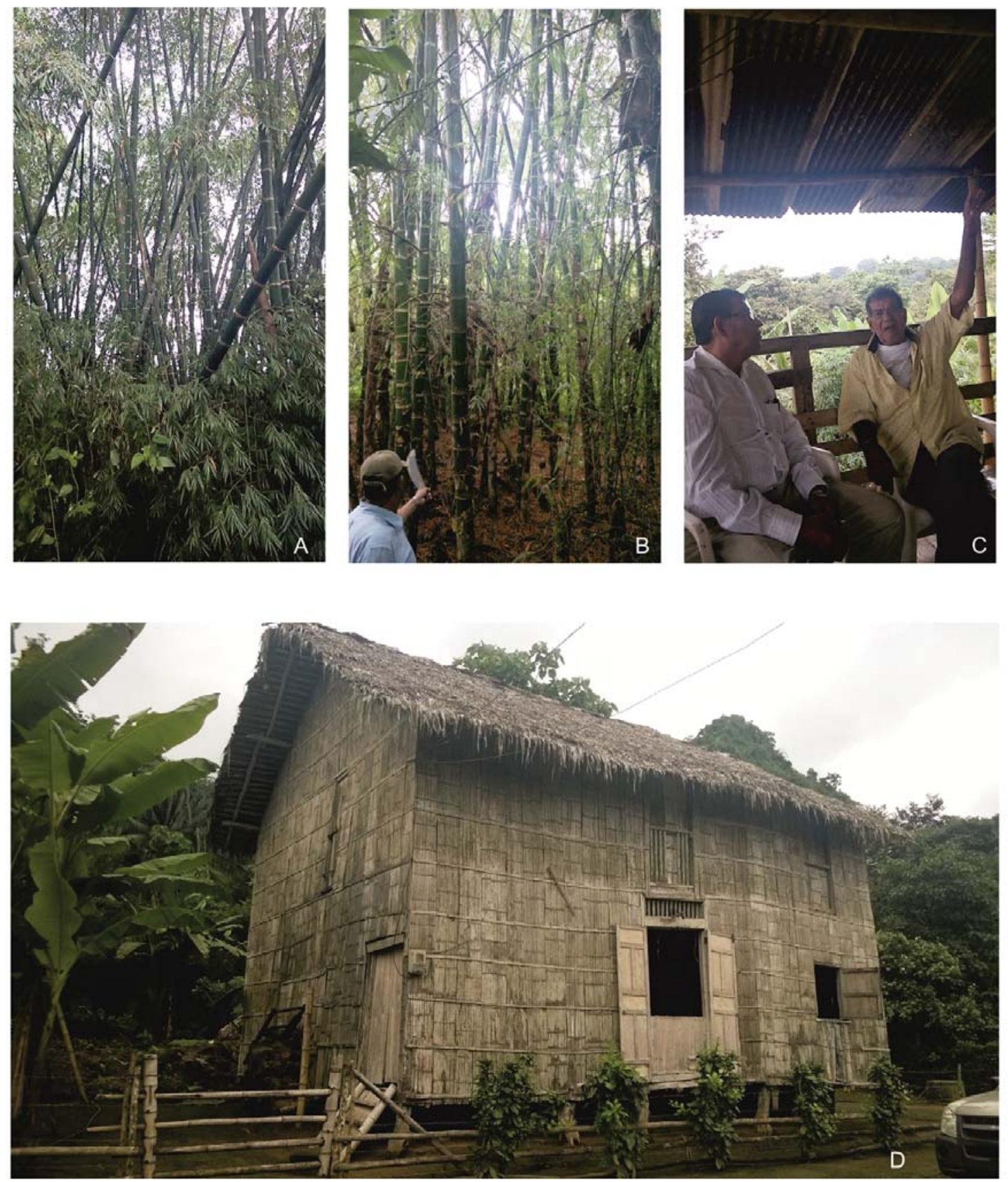

Figura 2. a) Caña guadúa; b) comprobación de la madurez; c) entrevistas a artesanos de Cabo de Hacha, Jipijapa; d) casa rural palafítica en Alhajuela, Portoviejo.

En torno a su explotación existe un extenso bagaje cultural. El análisis etnográfico de la guadúa ha combinado técnicas de observación descriptiva con entrevistas específicas (Bernard 2006: 211-212) y caracterización de los procesos de corte y desbastado. Para ello se realizó un total de 25 entrevistas en talleres de explotación rural (Figura 2c), a lo largo del sector central y meridional de la provincia de Manabí. También se elaboraron dos estudios micro-espaciales, en los que se vincularon espacios de producción y áreas urbanas consumidoras próximas (Figura 3).

El primero de los sectores se situó en el cantón de Jipijapa. Los espacios de concentración de guadúa más importantes se extienden entre 8 y $12 \mathrm{~km}$ al oeste del núcleo urbano, en las laderas que limitan con el vecino cantón de 24 de Mayo. Allí 


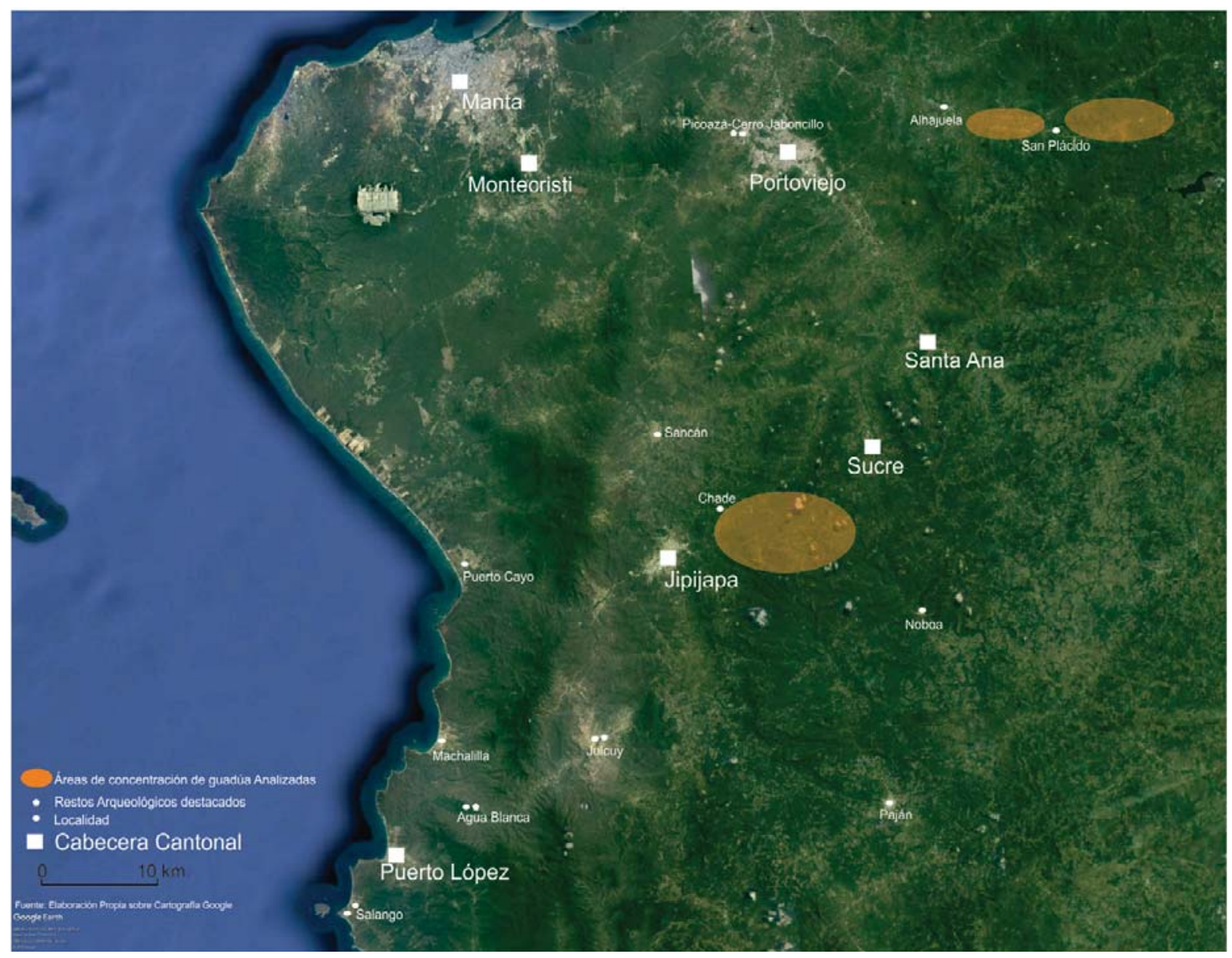

Figura 3. Área de intervención.

se produce la mayor parte de la producción que alimenta un territorio de algo más de $60 \mathrm{~km}$ de radio. Se trata de una producción campesina, adquirida por intermediario a través de relaciones monetarias. El transporte de la caña se realiza incluso hacia sectores urbanos de mayor tamaño, como Manta y Montecristi. Junto a los sitios de explotación, se han localizado pequeños talleres de transformación. Los resultados obtenidos en Jipijapa se han comparado con los alcanzados en las localidades de la Alhajuela y San Plácido, en el vecino cantón de Portoviejo, a $30 \mathrm{~km}$ de la capital provincial, y con unas características geográficas similares. Las únicas diferencias detectadas giran en torno al volumen de la comercialización y el transporte, que es menor en el caso de los núcleos portovejenses.

El proceso de preparación y de la apertura de la caña, para su utilización en construcción a la manera de paños, se realiza por artesanos especializados, que concentran parte de la producción local cuando ésta se orienta al ámbito urbano. En zonas rurales, se simplifica la cadena de transformación, siendo los propios agricultores los que la emplean para el autoconsumo, cubriendo la totalidad de la cadena operativa. El periodo en que la caña debe ser cortada es una de las cuestiones fundamentales que asegura su empleo como material constructivo. Tradicionalmente, los campesinos optan por cortar la planta de acuerdo al ciclo lunar. El cuarto menguante suele ser el momento óptimo, ya que la savia de la planta circula más lentamente. Para ello, se golpea el tronco con una piedra o el reverso de un machete (Figura $2 b$ ) y se identifica la madurez de la planta dependiendo del sonido, aunque también pueden existir otros indicadores, 

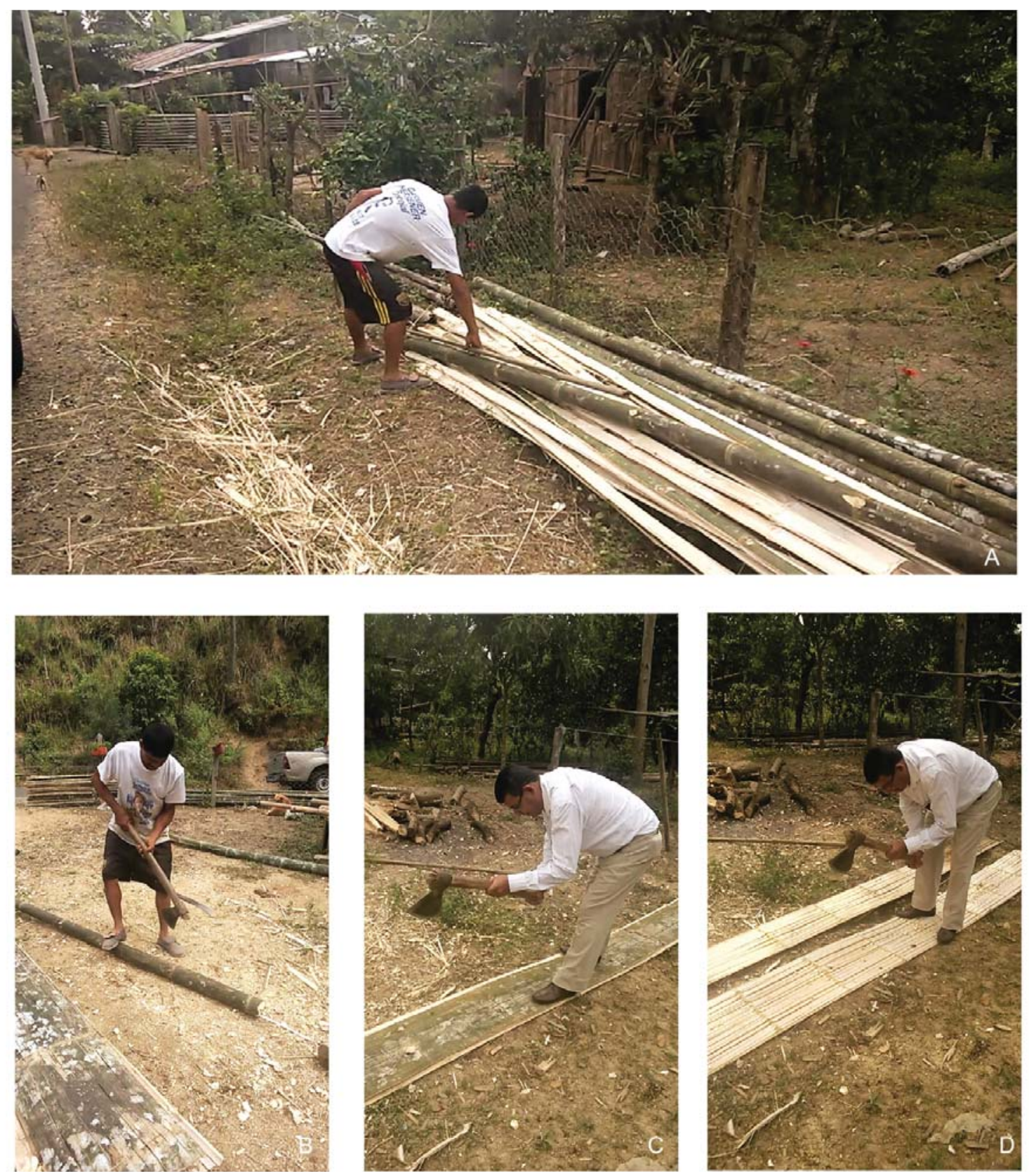

Figura 4. a) Medición de la caña en varas; b) empleo del hacha y de los pies en la apertura; c) preparación de los paños; d) finalización y eliminación de los nudos sobrantes.

como la presencia en los tallos de líquenes o musgo, y especialmente, el color grisáceo de los nudos, todo lo cual puede indicar que la planta se encuentra seca.

Sin embargo, a esta tradición se suman otras en las que hemos observado un criterio diferenciado. Los campesinos de mayor edad optan por cortar el bambú en el mes de octubre, tras el largo estiaje invernal que se inicia a finales de mayo o junio en el área costera. El corte siempre se produce por encima del tercer nudo, lo que asegura que la planta volverá a reproducirse. Frente al conocimiento tradicional, los botánicos defienden el tajo de la planta en el mes de mayo o junio, tras la finalización de la estación húmeda (diciembre-mayo) y el comienzo de la seca (Banik 2015: 214). En cuanto al podado, un «machetero» puede llegar a cortar hasta 10 cañas diarias, aunque en algunas ocasiones esa cifra es superada ampliamente. Frente a otras actividades campesinas, el trabajo de la caña es una labor masculina. 
La preparación final como material constructivo es relativamente sencilla (Figura 4). La apertura del tallo seco se realiza en minutos, manejando hachas, hachuelas y gurbias. Para ello, mientras se golpea por uno de los extremos, se hace girar el tronco con los pies. Una vez abierto, se le golpea para laminarlo. Finalmente, se cortan los restos de los nudos sobrantes con un machete. A partir de ese momento, los «paños» de caña se encuentran preparados para utilizarse en la construcción. Se emplean profusamente en paredes, tabiquería, de las viviendas rurales y urbanas, en muchas ocasiones asociadas a cubiertas vegetales como el cadi (Phytelephas aequatorialis) o el bijao (Calathea lutea). La demanda de caña dentro de relaciones de mercado ha provocado una cierta especialización, generando pequeños talleres sin que hayan desaparecido las actividades tradicionales en torno a la explotación del cacao, el café y el banano.

\subsection{La caña guadúa y su empleo en la casa manabita}

La construcción de la vivienda muestra tipologías diversas (Naranjo 2010: 327-343; Camino 2011), aunque es posible distinguir dos conjuntos: la rural y la urbana. La primera se levanta a modo de palafito (Figura 2d), estructurándose sobre un armazón de pies de madera que sujetan un conjunto de vigas horizontales, que sirven de armazón principal a un entramado de tiras que realizan función de suelo. A las vigas horizontales se clavan los paños de guadúa. Éstos últimos cumplen una función de forrado de la carpintería de armar o de lo «blanco». La casa urbana tiene importantes diferencias con la anterior (ver Figura 5b). Una de ellas es su articulación en dos pisos, aunque se han observado construcciones de tres. Predomina aquí la articulación de soportales, por la funcionalidad de almacén o comercio de la planta inferior que originalmente tuvieron las viviendas que se conservan (finales del siglo XIX, inicios del XX), durante el auge cacaotero y cafetalero. También una mayor unión con otros materiales como la madera o el enquinche. La cubierta aquí no es de materiales vegetales como en el mundo rural, sino que en algunos casos es en teja, aunque paulatinamente, a lo largo del siglo XX, se fue sustituyendo por zinc $\mathrm{y}$ aleaciones metálicas.

No se han observado cambios significativos en el proceso de elaboración entre una y otra, lo que permite defender la estabilidad de las técnicas y el contexto socioeconómico en torno al bambú. Los artesanos de mayor edad, sin embargo, prefieren la colocación de los paños de guadúa en horizontal y los más jóvenes en vertical. En el ensamblaje de la caña se utiliza clavo y alcayata (influencia colonial), con tiras de caña (latillas), aunque también se emplean bejucos (lianas) para unirlas. La unidad de medida gira todavía en torno a los sistemas métricos coloniales: la vara castellana $(0,83 \mathrm{~m})$ (Figura $4 \mathrm{a})$, acompañada de una medición más reducida en palmos $(0,20 \mathrm{~m})$. La vivienda de caña permite mantener condiciones climáticas suaves durante el periodo cálido tropical. $\mathrm{Su}$ abundancia asegura además un bajo costo y una fácil sustitución de los paños, manteniendo la estructura general de la casa.

El uso del bambú en la arquitectura, sin embargo, tiene varios inconvenientes. El riesgo más importante es el fuego. La frecuencia de éste en ciudades como Guayaquil, de la que se tiene amplia documentación histórica a lo largo de los siglos XVII-XVIII (1692, 1707, 1731, 1764, entre otros), obligó a la expresa prohibición de tejados en material perecedero (Laviana 2002: 45-50) y, de forma implícita, al 

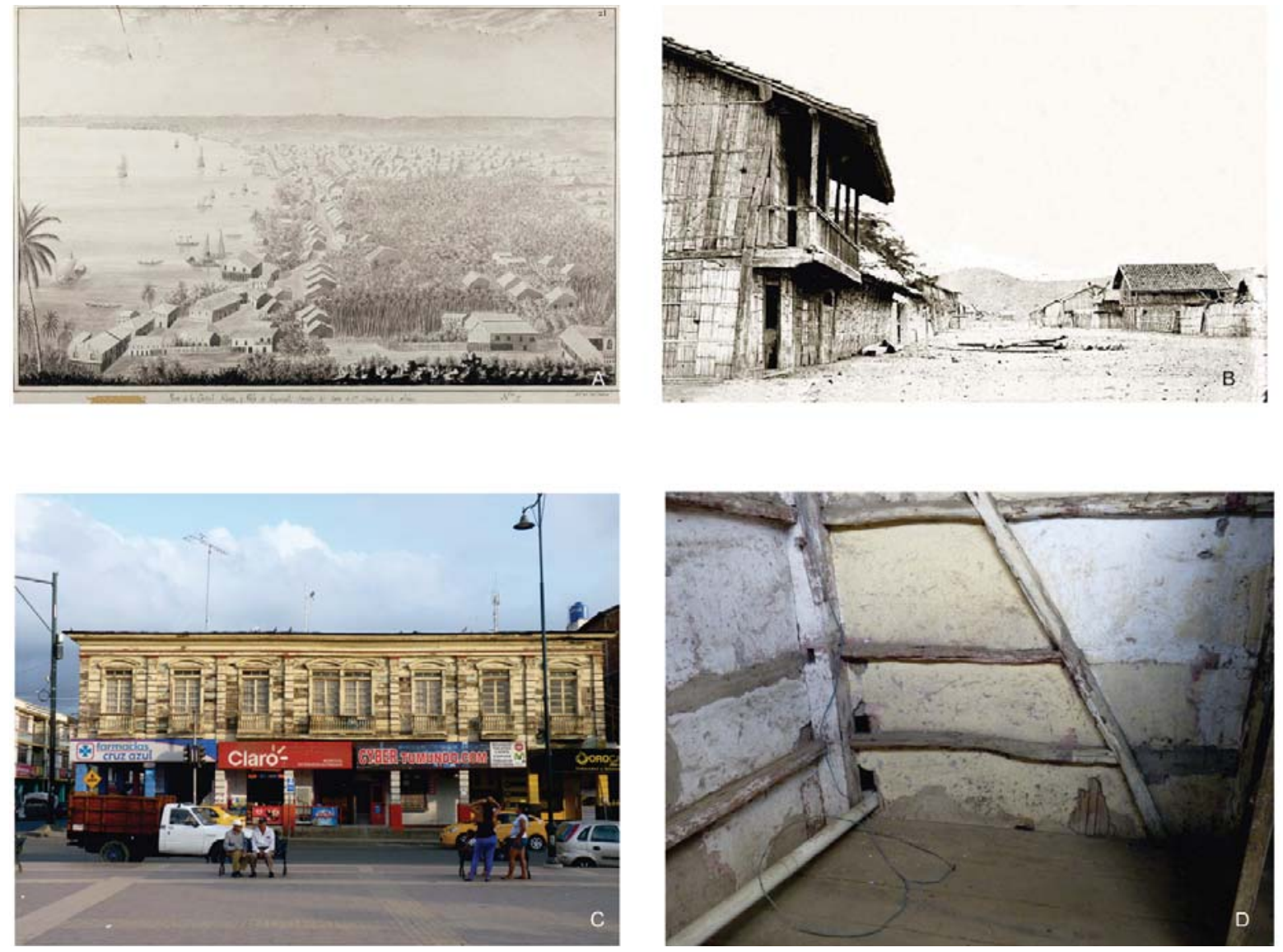

Figura 5. a) Vista de Guayaquil 1790 (Museo de América, Madrid); b) vista de las calles de Guayaquil 1863-1864 (CCHS, Madrid); c) casa Loor, Jipijapa; d) interior de la casa Loor con enquinche y caña como materiales de las paredes.

empleo de la caña. Sin embargo, ésta siguió siendo dominante en los arrabales de las ciudades costeras. Desde el siglo XVII, se vienen diseñando estrategias para mitigar estos efectos. La más utilizada ha sido la combinación de la caña con adobe, arcilla y excremento vacuno conformando el «enquinche». Este último, además, tiene otras ventajas. Una de ellas es su resistencia a los terremotos, tal como pone de manifiesto Alsedo, al describir su introducción desde Lima en la ciudad de Guayaquil, en torno a 1730: «...Y para mayor precaución de sus contingencias, se introdujo algún tiempo antes la fábrica de Quinchas y Bahareques, tomando el exemplo de la Ciudad de Lima, donde, por la pensión de los temblores, se inventó este modo de arquitectura civil, que authoriza al edificio en lo evidente, y resiste el estrago con la misma debilidad de la resistencia» (Alsedo y Herrera 1741: 11). En la mayor parte de las ocasiones, la caña se «pica», se divide en pequeños fragmentos, que refuerzan al adobe. Este último tiene una mayor resistencia al fuego y durabilidad que los simples paños de guadúa. En muchas ocasiones, además se encala tanto el interior como el exterior de la vivienda, lo que mejora la profilaxis frente a los insectos ${ }^{10}$.

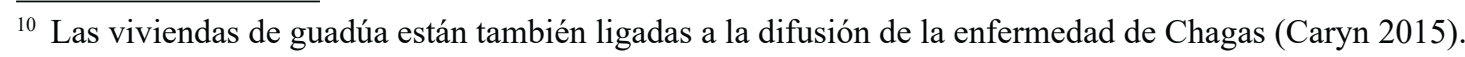




\subsection{El análisis de las fuentes históricas}

La arquitectura tradicional urbana que empleó la caña guadúa ${ }^{11}$ fue, en gran medida, mestiza, combinando los conocimientos del uso del material prehispánico ${ }^{12}$ con el aporte colonial. Uno de los lugares donde se produjo esa unión de elementos fue la Provincia de Guayaquil ${ }^{13}$, y especialmente en la ciudad homónima, que ejerció función de capital del sector costero desde el siglo XVII.

El núcleo de la ciudad se consolidó, desde mediados del siglo XVI, en una pequeña elevación. En 1605 su configuración se articulaba de la siguiente manera:

«Toda la ciudad tiene 61 casas, las 4 de ellas de posada [...]. Demás de esto tiene dos arrabales, en que hay aserraderos de madera y otras tiendas en que se labra jarcia para las naves de madera de cabuya. También está en el arrabal un convento de San Francisco [...]» (Ponce 1994: 15).

El uso de la madera se reducía en el campo, frente al bambú, siendo este último el único material constructivo en muchos casos:

«Las casas por la mayor parte son altas, con doblados, y cubiertas con teja lábranlas de madera amarilla y de roble y de cañas silvestres, que las hay tales, que hacen de ellas tablas de palmo y medio y de dos palmos de ancho» (Ponce 1994: 18). Algo más al Norte en el centro de la actual provincia de Manabí, el italiano G. Benzoni describía entre 1542-1555 la nueva ciudad de Portoviejo «ciudad habitada por españoles, que tiene unas veintidós casas de cañas cubiertas de paja [...]» (Benzoni 2000: 109).

Medio siglo después, en 1605, la situación poco había cambiado:

«[...] las casas son humildes y viles, hechas de cañas y barro, y cuando más de alguna madera, juntamente cubiertas de paja. Dicen que usan edificar bajo para seguridad de los temblores de tierra, que los solían padescer a menudo [...]» (Ponce 1994: 32).

De las lecturas de las fuentes documentales se observa, por tanto, que fue en las ciudades donde se produjo el mestizaje más intenso. Uno de los elementos más visibles de esta interacción lo encontramos en el astillero de Guayaquil, que comenzó a consolidarse en el último tercio del siglo XVI (1557) (Compte 2015: 472). Su función estuvo orientada desde el comienzo a la reparación de navíos y, a partir del siglo XVIII, a la construcción de barcos de carga. Su situación estratégica en las rutas comerciales del Pacífico hispánico permite entender su expansión y la aparición, en torno a él, de un núcleo de viviendas a partir del siglo XVIII, integrado por carpinteros de ribera o de lo blanco (obreros de maestranza, calafates y carpinteros). Estos obreros y maestros de la madera y la caña trabajaban indistintamente en la reparación naval o en la construcción de las casas de la Ciudad Nueva de Guayaquil, que se

\footnotetext{
11 Se ha realizado una revisión de las referencias existentes sobre la Arquitectura en caña guadúa en los dos principales archivos Históricos ecuatorianos: por un lado, el Archivo Histórico Nacional de Quito (ANE), y el Archivo Histórico del Guayas (Guayaquil). Gran parte de los datos, algunos muy concretos, sobre el empleo de la caña, escapan de los objetivos de este trabajo.

${ }^{12}$ El estudio de la arquitectura vernácula en la costa, y su origen prehispánico ha sido un elemento recurrente en la investigación desde mediados del siglo XX (ver Nurnberg et al. 1982 y Guinea 2010, entre otros).

13 Aunque los límites de la provincia fueron variando a lo largo del periodo colonial, las actuales provincias de Los Ríos, Manabí, Santa Elena y Guayas pueden ser consideradas las áreas tradicionales. A la caracterización cultural, la similitud de costumbres y de formas de vida, expansión económica agroexportadora, hay que sumar la función de capital regional, que viene realizando la ciudad de Guayaquil desde mediados del siglo XVII. El propio análisis geográfico del país mantiene el reconocimiento de esa unidad, al denominar a nuestra área de estudio «sector costa».
} 
fue instalando en torno al pequeño puerto en el siglo XVIII, tras su destrucción por un asalto pirata en 1687 (Laviana 2002: 30). El mestizaje entre las tradiciones de la carpintería de la Península Ibérica y la arquitectura indígena conformó una realidad nueva, combinándose por tanto el empleo de la madera con materiales livianos como la caña y el adobe. Pero al hábito de conocimientos, técnicas y experiencias se sumaban las características propias del colectivo de carpinteros, formado en la mayor parte de los casos por población de raza negra o mulata (Laviana 2002: 37), llegados a Guayaquil ante la fuerte demanda de mano de obra (Tardieu 2006) ${ }^{14}$.

La ubicación estratégica de Guayaquil, a medio camino entre Panamá y Lima, explica su crecimiento a lo largo del XVII y su despegue definitivo en el XVIII (Laviana 2002). La ciudad, además de la reparación de los navíos, aseguraba el aprovisionamiento de mercancías y el tránsito comercial hacia la sierra andina dentro de la Real Audiencia de Quito. Al comienzo del siglo XVIII, los marinos españoles Jorge Juan y Antonio de Ulloa, durante su visita a Guayaquil en 1736, escribieron la mejor descripción del empleo de la caña, las tradiciones que envuelve y su uso constructivo:

«El principal, y común material de las casas que pueblan las orillas de aquel río desde Guayaquil hacia arriba, se reduce a cañas [...]. Con ellas se fabrica todo el techo interior, las paredes, suelo, escaleras de las habitaciones chicas, pasamanos, y demás necesario, diferenciándose las grandes solamente en las bigas maestras, Estantes, y Escaleras, que son de madera. El methodo, con que las fabrican, es clavar en el suelo ocho, diez, o doce horcones (más, o menos según la capacidad, que ha de tener) y de bastante largo; porque toda la habitación es en lo alto: después atraviesan vigas de unos a otros, para sujetarlos, levantadas del suelo como quatro, ó cinco varas. Sobre ellas se ponen cañas de aquellas gruesas, que vienen a ser las Bigas intermedias, y encima tienden Tablas hechas de las mismas Cañas, cuyo ancho es de pie, y medio [...].

Porque cuando se les ofrece hacer casa, entran por los esteros en una canoíta pequeña, y en el monte más inmediato con solo su Machete cortan la cantidad de cañas, que han menester, la vijahua, y bejucos conducido todo a la orilla, forman con las mismas cañas una balza, sobre la cual cargan los demás adherentes: dejando ir río abajo hasta el paraje, en donde la han de hacer, y allí la plantifican, amarrando con los Bejucos lo que havian de clavar. Y en cortos días la tienen concluida con todos los repartimientos que necesitan. Habiendo algunas tan capaces, que no ceden en esto a las de Madera [...]» (Juan y Ulloa 1748: 258-260).

A principios del siglo XIX, la actividad naval había quedado en un segundo plano, frente al crecimiento del puerto como vía principal de salida del cacao, durante su primera gran expansión por el mercado internacional entre 1750 y 1830 (Chiriboga 2013). Es en la segunda mitad del siglo XVIII cuando comienzan a definirse la estrecha relación entre la arquitectura en caña y el comercio. La guadúa, un material humilde, la tierra, la paja (enquinche) y la madera se convertirán en los materiales que caracterizarán la evolución arquitectónica que se producirá en la costa desde principios del siglo XIX ${ }^{15}$. Todo ello coincide con la expansión del cultivo del cacao, que se convertirá en el primer gran sector exportador del país.

\footnotetext{
${ }_{14}$ Para una visión general de la esclavitud en la América hispánica ver Andrés-Gallego (2005). Para la Audiencia de Quito, sigue siendo un estudio fundamental el elaborado por Tardieu (2006).

${ }^{15}$ Existe una abundante documentación gráfica sobre la costa a lo largo del siglo XIX. A modo de ejemplo, las fotografías realizadas durante la Comisión Científica del Pacífico, llevada a cabo por la España isabelina entre 1862-1866, que muestra Guayaquil (Figura 5b). Es posible consultar la documentación de la expedición en http://
} 


\subsection{La identificación del patrimonio cultural en torno a la guadúa. Tipología urbana y constructiva}

Los precedentes de la arquitectura del periodo agroexportador cacaotero-cafetalero suponen una mezcla de influencias ${ }^{16}$ (Camino 2011). La más destacada, sin embargo, era la casa colonial española de dos pisos surgida desde el siglo XVI en la costa. Esta se organizaba en torno a un patio interior, alrededor del cual se centraban las actividades económicas y habitacionales. La planta inferior tenía espacios dedicados a oficinas, comercios o bodegas de almacenaje -de acuerdo con la actividad de su propietario-. En el patio trasero se ubicaba una letrina y en el patio interior los tanques que recogían el agua de lluvia. En el piso superior se ubicaba la vivienda propiamente dicha. La distribución se realizaba a partir del patio, desde donde se accedía a sala, comedor y dormitorios.

Sin embargo, junto a ella, fue siendo dominante en el ámbito urbano burgués y comercial un nuevo tipo de vivienda, que se consolidará definitivamente a inicios del siglo XIX. Ésta se caracterizó a partir de entonces por la ausencia de patio y el mantenimiento de soportales sobre pies de madera, que aseguraban el tránsito en las calles durante el largo periodo de lluvias (diciembre-mayo) y el mantenimiento de la actividad comercial. Una imagen interesante de este modelo urbano se puede observar en el dibujo realizado por el marinero José Cardero, integrante de la expedición Malaspina (1789-1794) (Cerezo 1987), y su representación de Guayaquil, desde el convento de Santo Domingo en la Ciudad Vieja (1790) (Figura $5 \mathrm{a}^{17}$ ), en el que se distingue la ausencia de patios en la Ciudad Nueva. Es posible vislumbrar también la construcción en caña y los pies de madera a modo de soportales. Los ambientes de la vivienda urbana, por tanto, se organizaron en torno a criterios de autosuficiencia y división social y productiva.

La introducción de los productos agrarios ecuatorianos en la red de intercambio global permitió la concentración de grandes fortunas, muchas de ellas con capacidad para residir en capitales como París y Londres (Maiguashca 2012: 80). El contacto de esta oligarquía con los hábitos de clase europeos, junto con la llegada de comerciantes foráneos, explica los cambios que sufre la arquitectura a lo largo del siglo XIX en el ámbito urbano. Éstos responden, por tanto, a esas nuevas influencias, aunque con una adaptación de los materiales, que siguen siendo la madera y la caña. Entre los elementos nuevos, destaca la posición de la vivienda burguesa en el contexto urbano, organizada mayoritariamente como núcleo unifamiliar. A finales del siglo XIX surgen viviendas plurifamiliares, más extensas, que responden a la conformación de linajes comerciales.

Junto a los complejos habitacionales urbanos, aparecen las quintas, o residencias de descanso en las afueras de las áreas productivas. No se trata de un modelo comparable a la hacienda, que tiene unas connotaciones diferentes -el control agrario

www.pacifico.csic.es/uym3/xml.htm. La Biblioteca del Centro de Ciencias Humanas y Sociales del CSIC (Madrid), conserva la totalidad de la documentación de la expedición digitalizada.

${ }^{16}$ En la elaboración de la tipología presentada, y su aplicación sobre Jipijapa, se ha seguido la planteada por Miguel Camino (Camino 2011). Los criterios tipológicos son extensible al conjunto de Casas Históricas de Manabí.

${ }_{17}$ Museo de América, Madrid. También en Ministerio de Cultura y Educación, a través del Archivo Ceres http:// ceres.mcu.es/pages/ResultSearch?Museo=MAM\&txtSimpleSearch=Vista\%20de\%20Guayaquil\&simpleSearch=0\&hip ertextSearch=1\&search=simple\&MuseumsSearch=MAM\%7C\&MuseumsRolSearch=11\&. Consultado 11 de diciembre de 2016. 
directo- y que es más frecuente en el sector andino del país, sino la aparición de la vivienda de descanso de origen francés. A lo largo de la primera mitad del siglo XX, surgen también nuevos materiales: la aparición del zinc, como sustituto de las tejas, o del hormigón en la tercera década de la centuria, que se combina con el enquinche, entre otros.

Las diversas crisis en el sector cacaotero, a finales del siglo XIX e inicios del siglo XX, fueron paliadas, en cierta medida, con el surgimiento del cultivo del café que, aunque sobre patrones similares a la expansión del sector agroexportador en el siglo XIX, mantiene algunos matices. Uno de ellos es una localización geográfica más marcada, como resultado de la concentración de la producción en áreas concretas, como ocurrió con el sur de la provincia de Manabí. Es en esta parte de la costa donde el sector económico se mantendrá en crecimiento hasta los años 70 , con parámetros similares a las estructuras de producción y de desigualdad consolidadas a finales del siglo XIX e inicios del XX. Desde el punto de vista arquitectónico, se continuará con las tipologías anteriores. La capacidad económica de los años 20 y 30 permitirá también la importación de ideas y asimismo de materiales y diseños (lo que explica la primera penetración del hormigón en el sector costero). Sin embargo, el sector cafetalero vivirá una debacle especialmente intensa desde mediados de los 80 , con la práctica desaparición de la producción cafetalera en la costa ecuatoriana y el comienzo de un proceso de profunda depresión económica, que todavía continúa.

Junto a la vivienda urbana, desde el periodo colonial los españoles de menor rango, y los mestizos descendientes de españoles e indígenas, construyeron sus casas, siguiendo el modelo anterior, pero a menor escala, y con una tendencia a la desaparición del patio más marcada. Todavía es posible observarlas en zonas rurales. Mantienen una planta rectangular, sobre pies de madera, en muchas ocasiones, con dos pisos. El superior realiza función de alcoba frente al inferior que, de manera poco definida, supone un área de descanso y cocina (ver Figura 3d). Aunque se mantiene la tipología, sin embargo, las tres últimas décadas suponen la penetración del ladrillo y el hormigón que, lentamente, sustituyen a los materiales tradicionales. Es un proceso mucho más visible en el ámbito urbano. La escasa adaptación de estos materiales, junto a los defectos en los diseños, explica, por otro lado, la intensa afección sísmica.

\subsection{Diseño de un modelo de planificación: protección y sensibilización social}

La investigación ha conllevado una revisión crítica de gran parte del inventario del Patrimonio Cultural Inmueble en el sector costero (provincia de Manabí). El Instituto Nacional de Patrimonio Cultural del Ecuador (INPC) tiene identificados un total de 258 inmuebles históricos ${ }^{18}$, la mayor parte de ellos $(82 \%)$ con una cronología de construcción que no supera los 100 años. Existe un reducido conjunto de casas patrimoniales que fueron levantadas entre 1875-1900. Algunas de ellas se integran en Centros Históricos bien delimitados de la provincia de Manabí (Jipijapa, Montecristi, Bahía de Caráquez, Olmedo, Noboa, Sucre y Manta), que terminaron de conformarse en las tres primeras décadas del siglo XX. A pesar de lo extenso, aparentemente, del inventario, éste se reduce al ámbito urbano. El grueso de las viviendas se

\footnotetext{
${ }^{18}$ Los datos de nuestro trabajo han sido agregados al Sistema de Información del Patrimonio Cultural Ecuatoriano (SIPCE), elaborado por el INPC.
} 
encuentra en un estado de deterioro significativo. La mayor parte de ellas se encuentran en manos privadas y los procesos de articulación de un modelo de protección han sido reducidos. Las actuaciones gubernamentales hasta la fecha se han limitado a un inventario de los bienes existentes, pero sin la promoción de medidas de salvaguarda reales. De manera excepcional, existe la recuperación de espacios concretos, fuera de criterios generales, optando por la conservación de bienes individuales. No existe, por otro lado, un inventario sistemático de la vivienda rural, lo que reduce en la práctica la elaboración inicial de modelos de protección del patrimonio cultural a una consolidación de los elementos materiales y simbólicos de las élites (Troncoso y Almirón 2005; Poria y Asworth 2009; González-Hernández 2013).

Ante el enorme número de viviendas que necesitan una actuación, diseñamos una estrategia inicial orientada a la creación de modelos de protección a pequeña escala, que permitieran la participación de la ciudadanía como un elemento añadido para la protección del patrimonio arquitectónico. El diseño inicial se ha aplicado sobre la ciudad de Jipijapa, uno de los centros más importantes del sector agroexportador durante el siglo XIX, buscando unir iniciativas locales de conservación y difusión, con capacidad para reproducirse en otras áreas de la provincia. Ésta se ha convertido en un «pequeño laboratorio» en el que se ha pretendido aunar realidades contrapuestas.

El estudio ha tenido como uno de sus elementos centrales la revisión del Inventario elaborado por el INPC en el año 2010, rediseñando modelos de zonificación y protección ${ }^{19}$, que se concretó en la elaboración de un documento de Declaratoria de valorización nacional ${ }^{20}$. La investigación ha conllevado el levantamiento arquitectónico y fotogramétrico de la trama urbana y de las viviendas, de acuerdo a los principios de la Arqueología de la Arquitectura (Caballero y Escribano 1996), con el fin de distinguir las características principales de ellas y los procesos de cambio durante su existencia. La revisión ha permitido constatar la desaparición de algunos edificios, desde el año 2010, y el deterioro generalizado de la mayoría. Sobre el conjunto inicial, de treinta edificaciones con las que el Estado ecuatoriano contaba en su Inventario, aquéllas que aúnan características tipológicas, de conservación y en torno a las cuales existe un acuerdo de desarrollo de su difusión, se han reducido a diecisiete.

Frente al diseño «vertical» de la investigación sobre una base conceptual «clásica» y hasta cierto punto estandarizada, se ha intentado contrastar las iniciativas «gubernamentales», en las que hay que sumar al Gobierno local, con la percepción con la que cuentan los ciudadanos de la iniciativa. Ésta se ha analizado a partir de tres variables: necesidad de conservación del patrimonio cultural del municipio, el patrimonio cultural como recurso turístico y, por último, un análisis de la aplicación de políticas de conservación mediante 400 encuestas a ciudadanos de Jipijapa ${ }^{21}$. Por

\footnotetext{
${ }^{19}$ Se han analizado todas las edificaciones existentes entre 1890 y 1940 , conformando un conjunto de 30 edificaciones. Al mismo tiempo, se han analizado aspectos funcionales, y transformación de los espacios, readecuación de los interiores, y características urbanas y de conservación de los inmuebles.

${ }^{20}$ La definitiva aprobación de la Declaratoria de la Ciudad de Jipijapa como Ciudad Patrimonio del Ecuador se ha producido en el mes de junio de 2017 (Acuerdo Ministerial DM 2017-019, del 15 de junio). Su refrendo institucional no supone una alteración de la discusión de resultados de este trabajo.

${ }^{21}$ La muestra se ha realizado sobre mayores de 18 años. No se ha tenido en cuenta segmentación por género o por franjas de edad. El total de la población de Jipijapa, de acuerdo al censo de 2010 es de 71083 habitantes. La población urbana representa el 56,59\% del total poblacional. El análisis de una muestra con un grado de confianza del $95 \%$ se sitúa en 382 encuestas. Las entrevistas a propietarios se ajustaron inicialmente al número de viviendas inventariadas por el INPC (30), aunque sólo fue posible entrevistar a 24. El margen de confianza se sitúa en este caso en un $81,74 \%$.
} 
otro lado, se han realizado entrevistas específicas a los propietarios de las viviendas, que se han incluido en el Documento de Declaratoria, con el objetivo de poder establecer las dificultades en la articulación de un modelo de protección del patrimonio cultural construido.

\section{Resultados y discusión}

\subsection{Tipologías arquitectónicas y paisajes culturales}

El estudio realizado en Jipijapa ha permitido ampliar las clasificaciones tipológicas que se han planteado en diversos trabajos en torno a la construcción en caña guadúa (Camino 2011), su evolución histórica y sincretismo. El conjunto urbano sigue siendo el más representativo de Manabí. La consolidación del centro histórico se produjo a lo largo del siglo XVII, mediante la creación de un área central a modo de plaza, enmarcada en torno a cuatro calles. A lo largo del siglo XIX, se produce la expansión de la ciudad hacia el noroeste, coincidiendo con la vía Noboa-24 de Mayo (Figura 6a), que eran los espacios geográficos donde se consolidó la producción cacaotera y cafetalera. En él se han podido distinguir cuatro tipos: villas periurbanas, viviendas burguesas plurifamiliares, viviendas-comercio unifamiliar y espacios de producción y almacenamiento.

- Villas periurbanas. El ejemplo más paradigmático en toda la provincia es la Quinta Thalía (1876) (Figura 6b). Diseñada imitando las casas parisinas de campo del último tercio del siglo XIX, su influencia europea alcanza su punto máximo en los jardines. La fachada es el elemento principal de la vivienda, articulada a partir de un mirador. Su organización en una planta tiene al salón como el elemento principal. Los materiales siguen siendo los tradicionales: madera, caña, revestida de enquinche, junto a cubierta de zinc, sobre viguería de madera.

- Viviendas burguesas plurifamiliares. Se trata de grandes espacios habitacionales, propios de la clase burguesa adinerada que se constituyó a finales del siglo XIX. Su tamaño permite la permanencia en la vivienda paterna de los herederos. En el caso de Jipijapa, la más emblemática es la casa Loor (1910) (Figura 6c). La importancia de la familia se asocia a la posición dominante en el entramado urbano. En este caso, la construcción emplea madera y diseño neoclásico, junto a enquinche y caña guadúa en el interior. Además de la casa Loor, hay otras construidas en los años 30 del siglo XX, como la casa ZavalaBaque y la Bustamante. Esta última tiene una planta inferior en hormigón, que muestra una mayor penetración de nuevos materiales, aunque manteniendo un marcado clasicismo en el interior. Su diseño es significativamente distinto al resto de las casas urbanas de Jipijapa. Cuenta con una gran terraza y un espacio trasero, a modo de patio, que se utilizaba para almacenar y secar el café. Al mismo tiempo, cuenta con un gran «mirador» aristocrático, por debajo del cual se estructuran diversos comercios.

- Viviendas-comercio unifamiliares. Se trata de viviendas sin patio. Su construcción supuso el hito a partir del cual se estructuró la unidad urbana inmediata (manzana). Su disposición en uno de los extremos aseguraba la visualización 

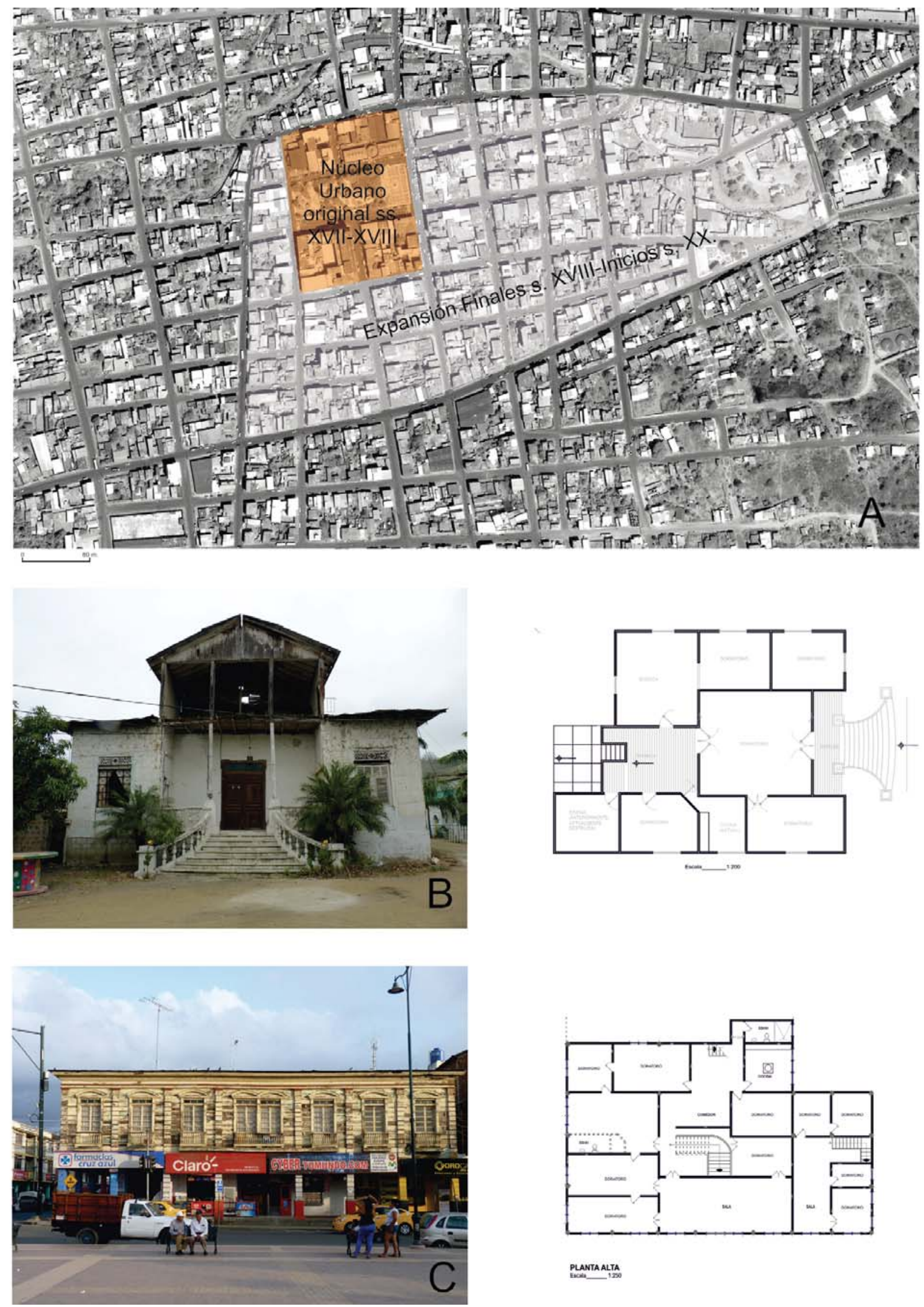

PLANTA ALTA

Figura 6. a) Evolución temporal del Centro Histórico de Jipijapa; b) Quinta Thalía (1876); c) casa Loor (1910). 
de varias calles. La vivienda se sitúa en la parte superior, siendo la inferior el espacio comercial y de almacén. En algunos casos, la influencia europea es tan significativa como para construir viviendas achaflanadas (Casa Guaranda, 1910) (Figura 7c). Junto a ésta, la que muestra un clasicismo más marcado es la Nieto Zavala, levantada en 1912. Es un tipo que pervivirá en el tiempo, con nuevos diseños en el tránsito entre los años 20-30. La casa Narváez (Figura 7a y e) y la Villacreces (Figura 7d), por ejemplo, se organizan en torno a tres espacios o crujías, con un gran salón y los dormitorios en torno a él. Destaca la escalera de caracol de la primera, que asciende hasta un mirador y que fue importada de Alemania en los años 30. La utilización de los materiales constructivos «modernos» es reducida, primando todavía los tradicionales. Sólo se observa el empleo del cemento en la fachada.

- Espacios de producción y almacenamiento. Junto a las residencias de los beneficiados por la acumulación de renta en torno al café y al cacao, existe un conjunto de espacios que enmarcan el proceso productivo. Es el caso de los edificios de las cooperativas agrícolas, la más antigua construida en 1908 (Figura $7 \mathrm{c}$ ), con rasgos similares al resto de las viviendas, combinando influencia europea y materiales locales.

Existe, sin embargo, un entorno inmediato al centro urbano sobre el que se ha realizado la investigación en el que no existe una única variable de análisis, desde criterios de recuperación ambiental y cultural. El cultivo de la guadúa está íntimamente ligado al mantenimiento del ecosistema boscoso inmediato. La generalización de la deforestación y la desaparición del bosque representan algunos de los rasgos más intensos de globalización, en la medida que responde a la aparición de actividades económicas nuevas (pastos para ganado vacuno) y la intensificación de la inmigración. Pero si la guadúa representa para el bosque el mantenimiento de la humedad, el café y el cacao suponen la conservación de gran parte de las especies arbóreas que aseguran el mantenimiento de la vegetación y las relaciones sociales, económicas y culturales en torno a ella.

\subsection{Un marco legal difuso, en una realidad compleja}

La legislación ecuatoriana vinculada al patrimonio cultural se encuentra en un proceso de transición. En noviembre de $2016^{22}$ se aprobó el proyecto Definitivo de Ley Orgánica de Cultura. La nueva norma pretende romper la centralización en la organización cultural del país, con algunos aspectos innovadores como la promoción de la «Cultura Viva Comunitaria $»^{23}$. Estas medidas, al menos conceptualmente, suponen una superación del marco globalizado de construcción de iniciativas de difusión en torno al patrimonio cultural (Prats 2005; Dormaels 2012: 14), mediante paradigmas de articulación vertical (grupo de expertos «orientan» a la comunidad). El objetivo

\footnotetext{
${ }^{22}$ El 10 de noviembre de 2016, por la Asamblea Nacional de la República del Ecuador: http://www.culturaypatrimonio. gob.ec/wp-content/uploads/downloads/2016/11/Version-Final-Ley-de-Cultura.pdf.

${ }^{23}$ Art. 4 del Proyecto Final de la Ley Orgánica de Cultura: Cultura viva Comunitaria. «Se promueve la cultura viva comunitaria, concebida como las expresiones artísticas y culturales que surgen de las comunas, comunidades, pueblos y nacionalidades, a partir de su cotidianidad. Es una experiencia que reconoce y potencia las identidades colectivas, el diálogo, la cooperación, la constitución de redes y la construcción comunitaria a través de la expresión de la cultura popular».
} 

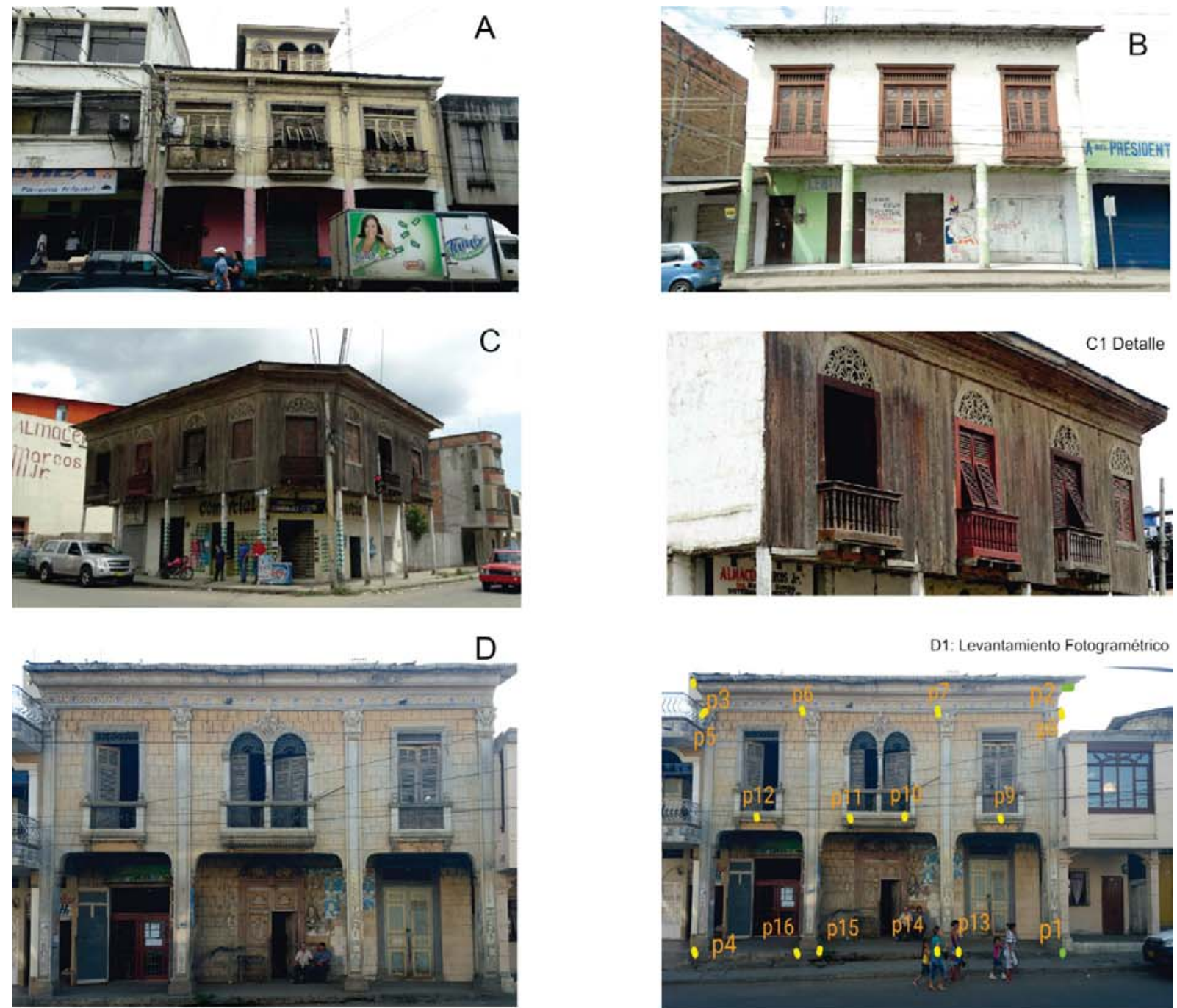

D1: Levantamiento Fotogramétrico
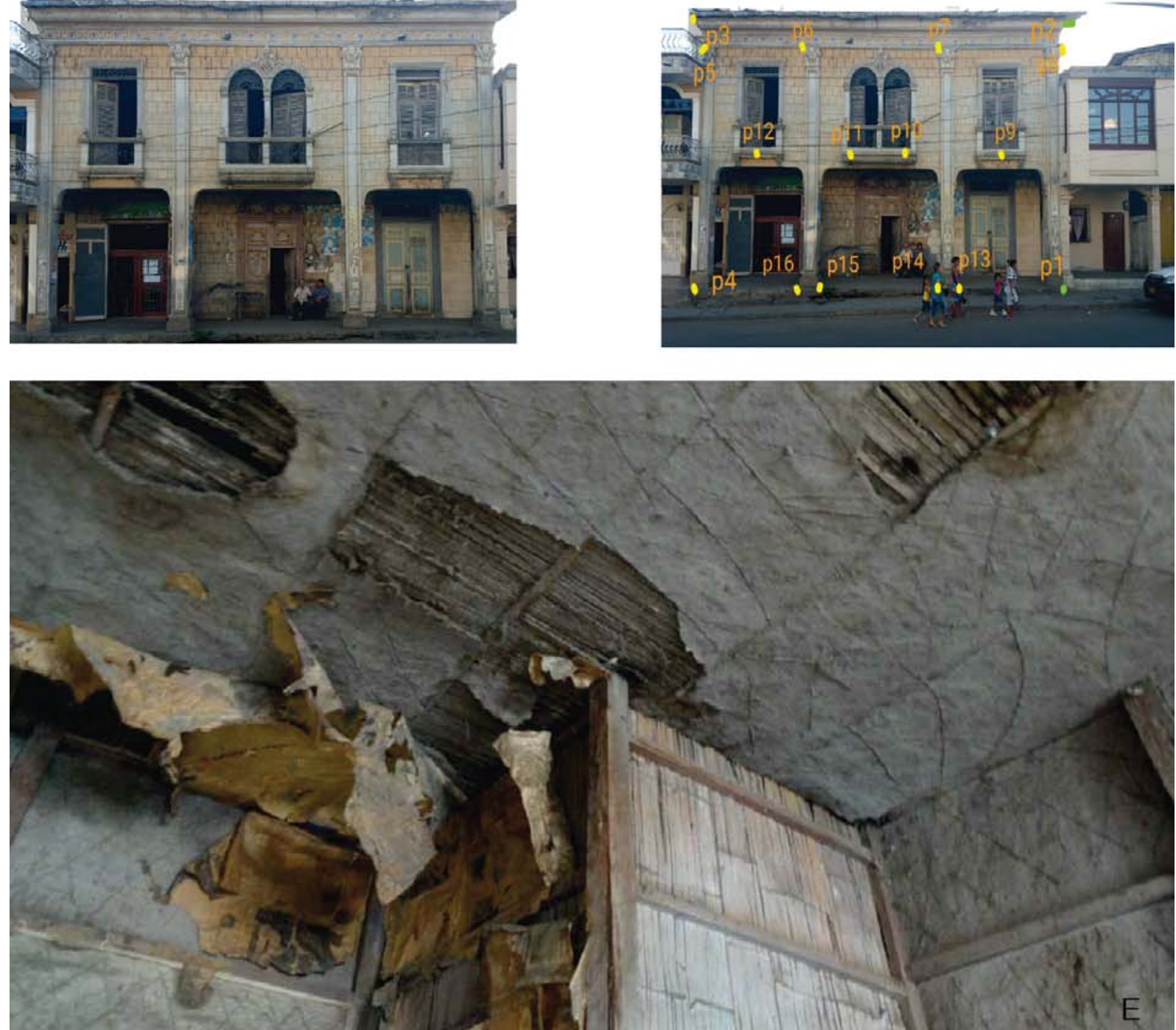

Figura 7: a) casa Narváez (1923); b) cooperativa cafetalera (1908); c) casa Guaranda (1910); d) casa Villacreces (1935); e) detalle interior de la casa Narváez en la que se distingue el empleo de la guadúa. 
es la creación de modelos que no supongan la ocultación de realidades culturales no «estandarizadas» (Lagunas 2006).

Otros de los elementos que han caracterizado la política nacional sobre patrimonio cultural, con puntos en común con la anterior, fueron avanzados en la primera mitad del año 2016. Nos referimos a la transferencia de competencias en cuestión de patrimonio cultural a los Gobiernos Municipales ${ }^{24}$ (GAD's). Supone de facto la cesión jurídica y económica del patrimonio cultural a los municipios, que son los encargados de sostener las iniciativas sobre él, a través de la generación de planes de conservación, difusión y también de ordenamiento jurídico. Éste es, sin duda, uno de los aspectos más controvertidos, porque la cesión se realizó con una limitada capacidad económica, lo que puede conllevar, paradójicamente, un efecto contrario al que se ha pretendido.

Junto a esta situación, existe otra todavía más compleja y que ha sido puesta de manifiesto recientemente por Álvarez (2016), subrayando la escasa capacidad durante los dos últimos decenios del sistema educativo ecuatoriano para establecer de manera sólida la formación de expertos en patrimonio cultural. Todo ello puede conllevar la continuidad de la dificultad para generar una gestión efectiva, en una época de rápida «homogeneización» cultural.

\subsection{Institucionalización definida en un entorno de dificultad de desarrollo de iniciativas locales}

Uno de los aspectos más complejos en torno a la protección del patrimonio cultural arquitectónico construido en guadúa, está siendo su difícil conversión en el siempre difuso concepto de «turismo». El Ministerio de Turismo del Ecuador desarrolló en el año 2007 una intensa actuación en la provincia de Manabí, con la que pretendió orientar las iniciativas de desarrollo local ${ }^{25}$. La activación, sin embargo, se ha producido en torno a una modelo de turismo costero clásico, que se ha aplicado sobre tres grandes áreas: Puerto Cayo (Jipijapa), Puerto López, con algunas especificidades, y Crucita en el cantón de Portoviejo. Existen también apuestas significativas de difusión del patrimonio cultural, como la Ruta de «Spondylus», que recorre el sector costero de norte a sur, combinando naturaleza con espacios culturales, y que ha pretendido ser el eje principal de la apuesta turística de las provincias litorales. En torno a ella, sin embargo, no se ha producido todavía una consolidación de infraestructuras, modelos museográficos y posibilidades de sostenibilidad.

\footnotetext{
${ }^{24}$ Resolución No. 0004-CNC-2015 el Consejo Nacional de Competencias (Registro Oficial 514,3-IV-2015), mediante el que se acuerda «Transferir la competencia para preservar, mantener y difundir el patrimonio arquitectónico y cultural, y construir los espacios públicos para estos fines, a favor de los gobiernos autónomos descentralizados metropolitanos y municipales». También el «Ejercicio de la competencia de preservar, mantener y difundir el patrimonio cultural.- Corresponde a los gobiernos autónomos descentralizados municipales, formular, aprobar, ejecutar y evaluar los planes, programas y proyectos destinados a la preservación, mantenimiento y difusión del patrimonio arquitectónico, cultural y natural, de su circunscripción y construir los espacios públicos para estos fines».

${ }^{25}$ El inventario existente y diseñado por el Ministerio de Turismo entre los años 2006-2007, siegue siendo la base de análisis principal. Su falta de actualización en grandes áreas de la provincia de Manabí, explica las dificultades para conocer el estado del «Sector» tras el terremoto de abril de 2016. Uno de los autores fue invitado a participar en las reuniones organizadas por el Ministerio de Turismo y las distintas universidades del área, con el fin de actualizar los datos estadísticos y de recursos del Sur de Manabí. El proyecto que se desarrolló emprendido a nivel institucional, no contó con la participación activa de autoridades locales.
} 
Frente a este panorama de programas estatales no consolidados, hasta ahora el modelo más exitoso ha resultado la unión de turismo comunitario (Ponce y Falconí 2011) y su relación con el patrimonio cultural, como ha sido el conocido ejemplo de la comunidad de Agua Blanca (Puerto López). Se trata de una fórmula con una intensa participación comunitaria en torno al patrimonio arqueológico (McEwan y Silva 2011). Es una vía sugerente de desarrollo, que ha sido sometida a propuestas evaluativas (Endere y Zulaica 2015). A pesar del innegable éxito de la iniciativa de Agua Blanca, presenta particularidades que impiden la reproducción inmediata del modelo en el sector costero. Una de ellas es su situación dentro de uno de los Parques Nacionales del Ecuador (Parque Nacional de Machalilla). Otra es la intensa participación de un elemento intermedio que ha sido el que ha colaborado en la viabilidad del proyecto, conformado por el equipo de antropólogos que dirigieron las intervenciones arqueológicas y que realizaron la formación de parte de la Comunidad (McEwan y Silva 2011). Por último, está el reconocimiento jurídico de Agua Blanca como una entidad étnica específica, que se integra en el deseo de algunas comunidades costeras de convertirse en una «nación» dentro del propio Estado ecuatoriano (Hernández-Ramírez y Ruiz-Ballesteros 2011; Ruiz-Ballesteros 2012). Al mismo tiempo, existen indicadores inequívocos de elaboración de símbolos nuevos para adaptarse al mercado turístico global, mediante mensajes sencillos y efectivos. Uno de ellos, la llamada fiesta de la «balsa manteña», que se celebra el 12 de octubre, rememora el encuentro entre los primeros conquistadores europeos y las poblaciones locales en la costa ecuatoriana en el siglo XVI. Se trata de la articulación de un discurso dualista, que pretende presentar a la comunidad de Agua Blanca como foco de resistencia y de conservación de tradiciones. En realidad, se trata de una adaptación contemporánea que simbólicamente muestra la supervivencia de la comunidad frente a la «institucionalización», en medio de la globalidad.

El «modelo» de Agua Blanca se ha consolidado frente a otros programas «antagónicos» en su concepción inicial, como ha sido el gran yacimiento manteño de Cerro Jaboncillo (Portoviejo). Este último ha surgido en torno a un un programa de construcción nacional amplio, que toma como centro simbólico la vecina ciudad de Montecristi, lugar de nacimiento de uno de los héroes del periodo republicano ecuatoriano: Eloy Alfaro (1842-1912).

\subsection{El patrimonio cultural se observa como una realidad distante}

Se percibe una débil sensibilización social en torno al patrimonio cultural, definiendo a éste como un recurso valioso per se, más allá de visiones reduccionistas que sugieren su único valor como recurso económico. Nuestro estudio, centrado en un patrimonio «invisible», como es la arquitectura en caña, y con datos obtenidos en Jipijapa, sugiere algunos indicadores que muestran la necesidad de realizar iniciativas con una importante socialización participativa. El 62\% de la población encuestada considera un elemento «importante» el patrimonio cultural, entendiendo por éste la conservación, mantenimiento de tradiciones y costumbres en una época de globalidad. Un $89,50 \%$ considera que el desarrollo del turismo es primordial para su ciudad, en la medida que ofrece alternativas económicas. Sin embargo, un 73\% de los encuestados no percibe una política local o estatal encaminada a la protección del patrimonio cultural. 
Los datos muestran situaciones más complejas derivadas de que el fomento del «Turismo» o el mantenimiento del «Patrimonio Cultural» no es un proceso que sólo conlleve beneficios. La totalidad de las casas patrimoniales de Jipijapa se encuentran en manos privadas, una situación extensiva a toda la provincia. Un 33\% de los propietarios han mostrado su rechazo a la inclusión de su vivienda en un programa de difusión del patrimonio cultural de la ciudad. La mayoría de ellos subarrendaron los inmuebles hace años y no viven habitualmente en Jipijapa.

Esta desconfianza se une al desconocimiento de las ventajas por la posesión y conservación del patrimonio cultural inmueble. La legislación ecuatoriana establece la reducción en un 50\% de los impuestos municipales ${ }^{26}$ y la exoneración de éstos durante 5 años si se realizan labores de restauración, avaladas por la Administración pública. Sin embargo el $95 \%$ de los propietarios desconocían la medida. La mayor parte de los propietarios (88\%) rechazan de plano la inclusión de su casa en programas de restauración y conservación, si éstos conllevan alguna forma de desembolso económico por su parte. El 90\% de los propietarios alude al incumplimiento de promesas por parte de las instituciones para promover la conservación de su vivienda.

El ejemplo de Jipijapa, y la escasa visibilidad por parte de la ciudadanía de medidas reales de intervención sobre el patrimonio cultural, explica la destrucción de parte del patrimonio inmueble tras el terremoto del 16 de abril de 2016. Ello se advierte con especial virulencia en los cantones más afectados, como Jama o Pedernales, pero también en otros como Portoviejo o Sucre. De acuerdo con los datos del INPC, se han demolido tras el terremoto un total de 53 casas patrimoniales, lo que representa un $18,79 \%$ del inventario existente. De los 28 conjuntos urbanos, 15 tienen un grado de afectación severa o mediana.

En el caso de Jipijapa los daños han sido mínimos. Sin embargo, el levantamiento de datos que se realizó entre julio y septiembre de 2016 ha mostrado que sobre un inventario en el año 2010 de treinta casas patrimoniales, se ha reducido el Proyecto de Declaratoria como Ciudad Patrimonio del Ecuador a diecisiete (2017). El drástico descenso es resultado de la mala conservación, que explica la demolición de algunas de ellas en los últimos años, junto al deseo de las familias de eliminar un bien que, creen, les va a ser expropiado, a los intereses especulativos y a una fuerte ambigüedad en los criterios por los que fueron catalogadas. Todo ello sugiere que las políticas estatales orientadas a la protección, difusión y desarrollo de alternativas económicas en torno al patrimonio cultural no son visibles ni han sido debatidas con la ciudadanía.

\section{Conclusiones}

La investigación se ha acercado a patrimonios culturales materiales en peligro en espacios de conformación de nuevos «paradigmas» culturales. Un parte significativa de la arquitectura en caña se ha visto afectada por el terremoto de abril de 2016. El empleo de la caña guadúa, sus tradiciones de trabajo y la arquitectura generada en torno a ella constituyen una realidad mestiza. Parte de ella se sitúa en núcleos

\footnotetext{
${ }^{26}$ Ley de Patrimonio Cultural, Codificación 27, Registro Oficial Suplemento 465 del 19 de Noviembre del 2004, Art. 21, http://www.unesco.org/culture/natlaws/media/pdf/ecuador/ec_codificacion_27_ley_de_patrimonio_cultural spaorof.pdf.
} 
urbanos y es un reflejo material de la participación de Ecuador en la primera gran expansión capitalista. Es también reflejo del surgimiento de relaciones de desigualdad y acumulación de renta en la conformación de la «globalidad». La investigación ha incidido sobre un lugar concreto, Jipijapa, aunque los interrogantes han sido regionales. Se ha conseguido combinar los ámbitos de la producción, la adaptación medioambiental, las tradiciones existentes ${ }^{27}$ y su estrecha relación con el cacao y el café, constituyendo una realidad cultural común. El desarrollo de proyectos de difusión en torno a la guadúa son el primer intento de superación en la construcción de «hitos» o espacios patrimoniales aislados a lo largo de Manabí.

La investigación ha subrayado, por otra parte, las dificultades para consolidar proyectos de desarrollo local, en los que existen múltiples actores. El patrimonio cultural en el sector costero del Ecuador se encuentra en una situación compleja, en la que se combinan diversas realidades. Las más significativas son la consolidación de las estructuras estatales postmodernas y el reforzamiento identitario de las comunidades locales con su dialéctica política (Benavides 2009, 2013), dentro de los parámetros de la globalización y fórmulas postcoloniales. En ese sentido debemos entender la construcción de discursos dualistas entre realidades prehispánicas y posthispánicas, reflejo de la contemporaneidad (Hernández-Ramírez y Ruiz-Ballesteros 2011).

Todo ello supone la conformación de nuevos «paradigmas» culturales y la marginalización de otros. En este último grupo deberíamos incluir el patrimonio arquitectónico cacaotero, pero también otros, de manera más explícita. Por ejemplo, la desaparición de parte de las artesanías populares, algunas con un marcado componente de género, visibles desde al menos el siglo XVIII (Castro et al. 2017), frente a la construcción de nuevos iconos como es el caso del sombrero de paja toquilla (Regalado 2010), avalados por la UNESCO. El análisis planteado necesita la ampliación de algunas variables en diversos aspectos: las pautas culturales y productivas en torno a la guadúa en el sector costero, y de manera amplia en Perú y Colombia, como resultado de un bagaje cultural con diversos puntos en común; por otro lado, la réplica de las condiciones y elementos sobre los que se puede desarrollar la protección de la guadúa a nivel microespacial, teniendo como sostén fundamental la nueva Ley Orgánica de Cultura ecuatoriana de 2016; y, por último, la necesidad de establecer una construcción identitaria en torno al patrimonio cultural capaz de aglutinar manifestaciones «antagónicas».

\section{Referencias}

Acosta, Alberto. 2006. Breve historia económica del Ecuador. Quito: Corporación Editora Nacional.

Alsedo y Herrera, Dionisio. 1741. Compendio histórico de la Provincia, partidos, ciudades, astilleros, ríos, puerto de Guayaquil en las costas del Mar del Sur. Madrid. Biblioteca Digital Hispánica, http://bdh.bne.es/bnesearch/detalle/bdh0000001065.

\footnotetext{
${ }^{27}$ El proceso de selección de los paradigmas explicativos, de los ítems antropológicos e históricos que se pretenden difundir, junto al establecimiento de un discurso determinado, implica una labor de reconceptualización del pasado, que debe ser revisada continuamente.
} 
Álvarez Litben, Silvia Graciela. 2016. «¿Es posible un patrimonio cultural para el Sumak Kawsay?: un largo camino por recorrer». PASOS. Revista de Turismo y Patrimonio Cultural 14 (1): 285-299.

Andrés-Gallego, José. 2005. La esclavitud en la América española. Madrid: Ediciones Encuentro.

Banik, Ratan Lal. 2015. «Harversting Techniques», en Bamboo: The Plant and its Uses, Tropical Forestry, Walter Liese y Michael Köhl, eds., pp. 193-226. Heidelberg: Springer International Publishing.

Benavides, Oswald Hugo. 2009. «Disciplining the Past, Policing the Present: The Postcolonial Landscape of Ecuadorian Nostalgia». Archaeologies 5 (1): 134-160.

- 2013. «Working/Touring the Past: Latin American Identity and the Political Frustration of Heritage». Journal of Historical Archaeology 17 (2): 245-260.

Benzoni, Girolamo. 2000. La historia del Mundo Nuovo. Guayaquil: Banco Central del Ecuador.

Bernard, Harvey Russell. 2006. Research Methods in Anthropology: Qualitative and Quantitative Approaches. Oxford: Altamira.

Caballero Zoreda, Luis y María Consuelo Escribano Velasco, coords. 1996. Arqueología de la arquitectura: el método arqueológico aplicado al proceso de estudio y de intervención en edificios históricos. Valladolid: Consejería de Educación y Cultura, Junta de Castilla y León.

Camino Solórzano, Miguel Ángel. 2011. «La caña guadúa en la provincia de Manabí y el litoral de Ecuador», en Construcción con tierra. Tecnología y arquitectura, congresos de arquitectura de tierra en Cuenca de Campos 2010/2011, pp. 205-212. Valladolid: Universidad de Valladolid.

Caryn, Bern. 2015. «Chagas’ Disease». The New England Journal of Medicine 373 (5): 456466.

Castro Priego, Manuel, Marcos Octavio Labrada y Edison Aroldo Chasing Guagua. 2017. «Mujer y tradición cerámica en la costa ecuatoriana: indicadores etnoarqueológicos», en $\mathrm{Mu}$ seos arqueológicos y género. Educando en igualdad, Lourdes Prados Torreira y Clara López Ruiz, eds., pp. 323-358. Madrid: Universidad Autónoma de Madrid.

Cerezo Martínez, Ricardo. 1987. La expedición Malaspina: 1789-1794, vol. 1. Madrid: Lunwerg Editores.

Chiriboga Vega, Manuel. 2013. Jornaleros, grandes propietarios y exportación cacaotera, 1790-1925. Quito: Corporación Editora Nacional.

Compte Guerrero, Florencio. 2015. «El aporte naval y de los carpinteros de ribera en la arquitectura tradicional de Guayaquil», en Actas del Noveno Congreso Nacional y Primer Congreso Internacional Hispanoamericano de Historia de la Construcción, pp. 471480. Madrid: Instituto Juan de Herrera.

Dormaels, Mathieu. 2012. «Identidad, comunidades y patrimonio Local: una nueva legitimidad social». Alteridades 22 (43): 9-19.

Endere, María Luz y María Laura Zulaica. 2015. «Sustentabilidad socio-cultural y Buen Vivir en sitios patrimoniales: evaluación del caso Agua Blanca, Ecuador». Ambiente \& Sociedade 18 (4): 265-290.

Fiedel, Stuart J. 2000. «The Peopling of the New World: Present Evidence, New Theories, and Future Directions». Journal of Archaeological Research 8 (1): 39-103.

González-Hernández, Guadalupe Margarita. 2013. «Urbis: de los imaginarios al fetichismo frente al debate de los centros históricos». Boletín Científico Sapiens Research 3 (2): 29-33. 
Guinea Bueno, Mercedes. 2010. «Un edificio enterrado ritualmente: la Estructura 1 del montículo J8 del sitio manteño de Japotó, Manabí, Ecuador». Bulletin de l'Institut Français d'Études Andines 39 (3): 503-530.

Hernández-Ramírez, Macarena y Esteban Ruiz-Ballesteros. 2011. «Etnogénesis como práctica. Arqueología y turismo en el pueblo Manta (Ecuador)». Antropólogos Iberoamericanos en Red 6 (2): 159-192.

Juan, Jorge y Antonio de Ulloa. 1748. Relación histórica del viage a la América Meridional hecho de orden de S. Mag. para medir algunos grados de meridiano terrestre y venir por ellos en conocimiento de la verdadera figura y magnitud de la Tierra: con otras varias observaciones astronómicas. Biblioteca Digital Hispánica, Madrid. http://bdh.bne. es/bnesearch/detalle/bdh0000046090.

Kleinn, Christoph y David Morales Hidalgo. 2006. «An Inventory of Guadua (Guadua angustifolia) Bamboo in the Coffee Region of Colombia». European Journal of Forest Research 125 (4): 361-368.

Lagunas Arias, David. 2006. «El espacio del turismo». Alteridades 16 (31): 119-129.

Lauria Santiago, Aldo. 1999. An Agrarian Republic: Commercial Agriculture and the Politics of Peasant Communities in El Salvador 1823-1914. Pittsburgh: University of Pittsburgh Press.

Laviana Cuetos, María Luisa. 2002. Guayaquil en el siglo XVIII. Recursos naturales y desarrollo económico. Guayaquil: Banco Central del Ecuador.

Maiguashca, Juan. 2012. «La incorporación del cacao ecuatoriano al mercado mundial entre 1840 y 1925, según los informes consulares». Procesos. Revista Ecuatoriana de Historia 35: 67-97.

Mcewan, Colin y María Isabel Silva. 2011. «Seats of Power and Iconographies of Identity in Ecuador. Unpacking the Collection», en Networks of Material and Social Agency in the Museum, A.C.S. Byrne, ed., pp. 249-265. Nueva York: Springer.

Mcmichael, Crystal H. 2014. «Bamboo-Dominated Forests and pre-Columbian Earthwork Formations in South-Western Amazonia». Journal of Biogeography 41 (9): 1733-1745.

Naranjo Villavicencio, Marcelo. 2010. La cultura popular en el Ecuador. Tomo IX, Manabí. Cuenca: Centro Interamericano de Artesanías y Artes Populares.

Nurnberg, David, Julio Estrada Ycaza y Olaf Holm. 1982. Arquitectura vernácula en el litoral. Archivo Histórico del Guayas 14. Guayaquil: Banco Central del Ecuador.

Olivier, Jean, Thierry Otto, Martin Roddaz, Pierre-Olivier Antoine, Ximena Londoño y Lynn G. Clark. 2009. «First Macrofossil Evidence of a pre-Holocene Thorny Bamboo cf. Guadua (Poaceae: Bambusoideae: Bambuseae: Guaduinae) in South-Western Amazonia (Madre de Dios- Perú)». Review of Palaeobotany and Palynology 153 (1-2): 1-7.

Pineo, Teodoro Ronn. 1994. «Guayaquil y su región en el segundo boom cacaotero (18701925)», en Historia y región en el Ecuador: 1830-1930, Juan Maiguashca, ed., pp. 251294. Quito: Corporación Editora Nacional.

Ponce, Juan y Fander Falconí. 2011. «Ecoturismo: emprendimientos populares como alternativa a un desarrollo excluyente», en Espacios en disputa: el turismo en Ecuador, Mercedes Prieto, ed., pp. 167-205. Quito: Flacso-Sede Ecuador.

Ponce Leyva, Pilar. 1994. Relaciones histórico-geográficas de la Audiencia de Quito siglos XVI-XIX. Quito: Abya-Yala.

Poria, Yaniv e Israel Gregory Ashworth. 2009. «Heritage Tourism-Current Resources for Conflict». Annals of Tourism Research 36 (3): 522-525.

Prats, Llorenç. 2005. «Concepto y gestión del patrimonio local». Cuadernos de Antropología Social 21: 17-35. 
Regalado Espinoza, Libertad. 2010. Las hebras que tejieron nuestra historia. Quito: Instituto Nacional de Patrimonio Cultural.

Rodríguez, J. Alexander, Isabel C. Sepúlveda, Juan C. Camargo García y Jesús H. Galvis Quintero. 2009. «Soil and Nutrient Loss under Different Vegetation Covers in Colombia's Andean Region/Pérdidas de suelo y nutrientes bajo diferentes coberturas vegetales en la zona andina de Colombia». Acta Agronómica 58 (3): 160-166.

Sick, Deborah. 1999. Farmers of the Golden Bean: Costa Rican Households and the Global Coffee Economy. Chicago: Northern Illinois University Press.

Striffler, Steve. 2002. In the Shadows of State and Capital: The United Fruit Company, Popular Struggle, and Agrarian Restructuring in Ecuador, 1900-1995. Durham: Duke University Press.

Tardieu, Jean Pierre. 2006. El negro en la Real Audiencia de Quito. Siglos XVI-XVIII. Quito: Ediciones Abya-Yala.

Troncoso Claudia y Analía Almirón. 2005. «Turismo y patrimonio. Hacia la relectura de sus relaciones». Revista Aportes y Transferencias 1 (9): 56-74. 